\title{
Experimental seasonal forecasts of low summer flows in the River Thames, UK, using Expert Systems
}

\author{
C. S. Wedgbrow ${ }^{1, *}$, R. L. Wilby ${ }^{2}$, H. R. Fox ${ }^{1}$ \\ ${ }^{1}$ Department of Geographical, Environmental and Earth Sciences, University of Derby, Kedleston Road, \\ Derby DE22 1GB, UK \\ ${ }^{2}$ Environment Agency, Trentside Offices, Nottingham NG2 5FA, UK
}

\begin{abstract}
Empirical seasonal forecasts of hydroclimatic variables are typically limited by unrealistic assumptions about stationarity, linearity and normality. Although empirical, Expert Systems (ES) are not bound by such formal data constraints and may be trained on continuous and categorical data simultaneously. Using an ES, summer flows for the River Thames, UK (1971 to 2001), were forecast with up to 6 mo lead-time from climate data from the preceding winter months. The ES models successfully forecast the correct sign of August flow anomalies up to $77 \%$ of the time and June to August anomalies $71 \%$ of the time. Forecasts of low flow (lowest quartile of the long-term average) in August and summer as a whole were correctly forecast 79 and $89 \%$ of the time, respectively. The models also correctly predicted below-average flows for the drought years of 1976, 1984, 1989 to 1992, 1995 and 1997. These extreme events would not have been captured by a forecast based on long-term climatology alone.
\end{abstract}

KEY WORDS: Seasonal forecasting $\cdot$ Expert System $\cdot$ Low flows $\cdot$ River Thames

\section{INTRODUCTION}

Seasonal outlooks are long-range forecasts with lead-times of more than $30 \mathrm{~d}$ (WMO 2002). Dynamical model forecasts rely on initial atmosphere-ocean boundary layer conditions and are limited by their coarse spatial resolution and simplified representations of ocean-atmosphere processes. Although they realistically simulate large-scale circulation, regional or local-scale features, rainfall and catchment scale processes are less well reproduced (Kilsby et al. 1998, Wilby 1998, Landman \& Mason 1999, Reason \& Mulenga 1999, Solman \& Nunez 1999, Wilby \& Wigley 2000, Goddard et al. 2001). Mismatches between the spatial resolutions of meteorological and hydrological models have also to be overcome (Rodda \& Rodda 1999).

Empirical seasonal forecasts are often limited by unrealistic assumptions about stationarity, linearity and normality and are affected by data availability (Kumar et al. 1995, Goddard et al. 2001). The choice of predictors may be restricted by the availability of high quality real-time and archived data. Although empirical, Expert Systems (ES) are not bound by formal data constraints. Data may be used from any distribution; it may be auto- or cross-correlated, and attribute-class relationships can be non-linear (Quinlan 1993, Jackson 1999). However, including correlated variables may (1) lead to redundant information, (2) produce overcomplicated models (if all covarying attributes are included) or (3) produce overly simple models (if only covarying attributes are included). ES may be trained on continuous and categorical data simultaneously.

Meteorological and climatological applications of ES include short-range forecasts of precipitation (Honghua et al. 1987, Conway 1989, Kumar et al. 1994), thunderstorm activity (Conway 1989), ice cover (Rodionov \& Assell 1999), visibility, winds and clouds 
(Rodionov \& Martin 1999), and weather pattern classification (Barry \& Carleton 2001). Despite these examples, none of the global seasonal to interannual forecasts listed in WMO (2003) are derived from an ES. With the exception of Wedgbrow (2003), ES have not been used for seasonal forecasts of either meteorological or hydrological variables in the UK. This study presents interim results of experimental seasonal forecasts of flows in the River Thames, UK, using an inductive ES. It is beyond the scope of this paper to consider the physical relationships between the predictor(s) and predictands; however, the physical legitimacy of the variables used are considered by Wedgbrow (2003) and by Wilby et al. (2004). A brief introduction to ES is given in Section 2, and the attribute and target data sets are described in Section 3. Section 4 describes the methods used to produce seasonal forecasts of mean flows in the River Thames, along with the cross validation procedure employed. The relative skills of the models compared with climatology, persistence and equivalent forecasts produced using Jack Knife Regression (JKR) are reported in Section 5 and discussed in Section 6. The final section summarizes the main conclusions and offers suggestions for future research.

\section{EXPERT SYSTEMS}

An ES classifies target variables (e.g. rainfall or river flow) according to predictor values (e.g. North Atlantic Oscillation or sea surface temperatures), in turn creating rules for prediction. The classification or rule making process may be 'hard coded' using expert knowledge (a rule-based ES) or automated (an inductive ES). Inductive algorithms systematically explore historical predictors to determine how well they predict the dependent variable. The ES generates prediction rules in the form of a decision tree or rule sets comprising 'IF...THEN' type statements. The attribute with the most information about the target is placed at the root of the decision tree (or becomes the first rule of the set). For example, a rule set for predicting river flow from area averages of geopotential height at $500 \mathrm{hPa}$ (Z500) and mean sea level pressure (MSLP) might look like:

$$
\begin{gathered}
\text { IF winter Z500 Mediterranean } \leq 5553.10 \mathrm{dm} \\
\ldots \text { AND MSLP Mediterranean } \leq 1020 \mathrm{hPa} \\
\ldots \text { AND MSLP Arctic } \leq 1010 \mathrm{hPa} \\
\text { THEN summer discharge }=43 \mathrm{cumecs}
\end{gathered}
$$

The number of rules required to classify a time series depends on series length, the number of attributes and the number of different target values. Though the actual threshold values may differ depending on the induction algorithm used, a useful predictor should be identified regardless of the algorithm type. Like other empirical methods, the skill of an ES depends on the quality and quantity of input data, and the predictability of the target variable(s); model accuracy is sensitive to data noise and data that are not stationary. The ES identifies the most useful predictors from a multivariate set of attributes by their proximity to the root (of a decision tree), their estimated accuracy (based on historical precedent) and from the number of examples that each rule was derived from.

The rules used to make a prediction may be traced and individual cases (years) cross-referenced (Forsyth \& Naylor 1985, Rodionov \& Martin 1996, 1999). This helps to analyse outliers and identify possible interrelationships between variables (e.g. between largescale atmospheric and oceanic variables and localscale hydrological or meteorological parameters). The complexities of climate predictor-predictand relationships may be hidden in black-box methods such as artificial neural networks. In contrast, the transparency of ES can provide useful insights for investigating the potential sensitivity of target variables to climate change.

Although statistical regression and rule induction are similar techniques, the terminology is different. Both use data comprising at least 1 predictor and a predictand and a transfer function is developed in both cases. From hereon 'attribute' replaces predictor and 'target' or 'class' replace predictand. Cases are referred to as 'examples'.

\section{DATA}

Winter rainfall and river flow are relatively poor attributes of summer (July to August) river flow in England and Wales, justifying the use of alternative largescale climate variables (Wedgbrow 2003). Several attributes are calculated as area averages (see Fig. 1), the domains based on field significant clusters of correlation between the gridded attributes and a regional runoff index (Wedgbrow 2003). Data for all variables are for 1950 to 2001. All attributes are January-February averages except for Arctic sea-ice (March) and Polar Eurasian pattern (POL, January). Previous research showed little or no improvement in the correlation between river flows in England and Wales and large-scale winter attributes using detrended data, supporting the use of raw rather than detrended time series for seasonal forecasts of flow in the River Thames (Wedgbrow 2003).

Monthly gridded $\left(5^{\circ} \times 10^{\circ}\right)$ Z500 are from the Northern Hemisphere Geopotential Height data set of the UK Meteorological Office (UKMO) and gridded $\left(1^{\circ} \times 1^{\circ}\right)$ sea-ice concentrations (SIC) are from the 
A

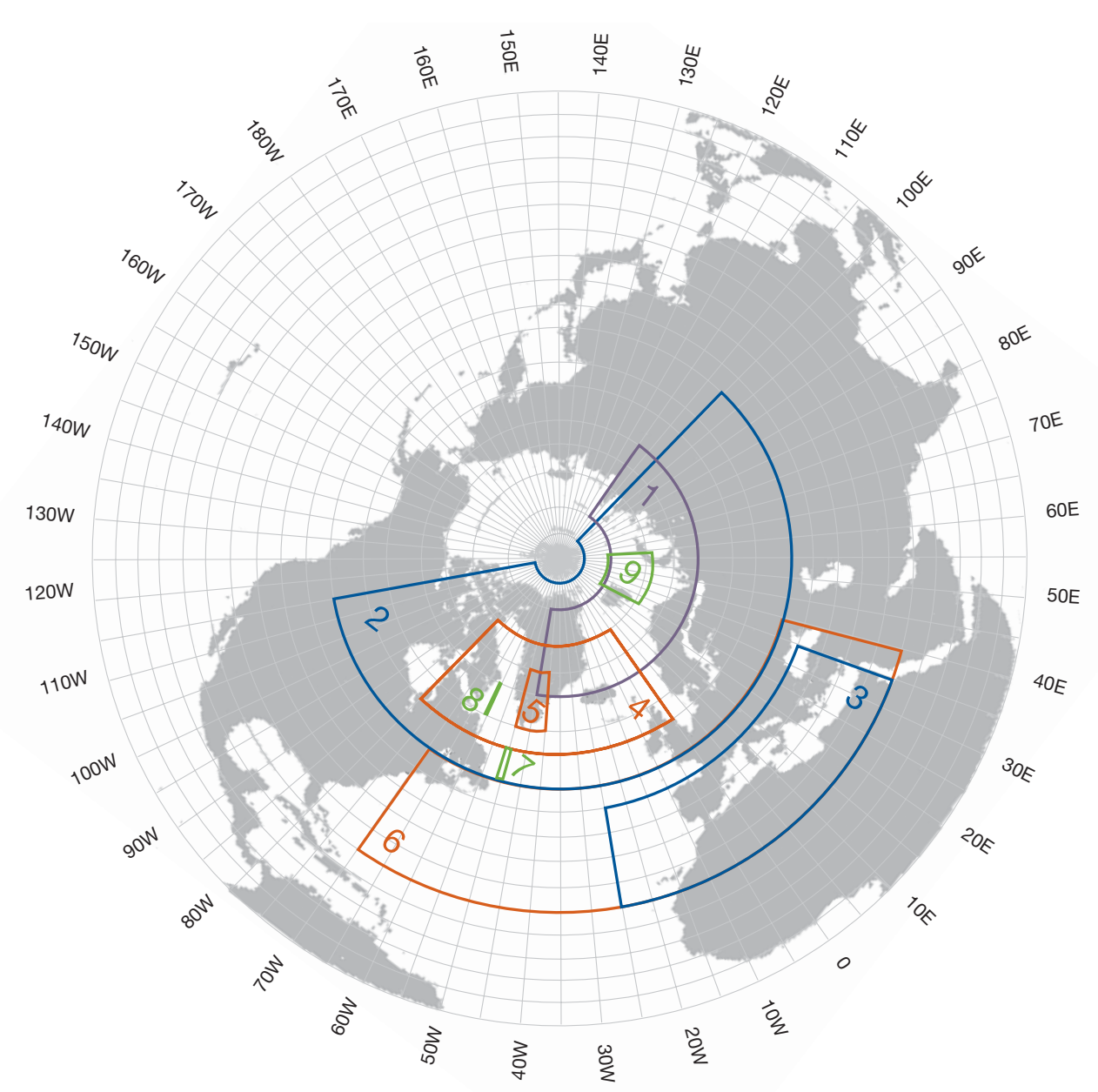

B

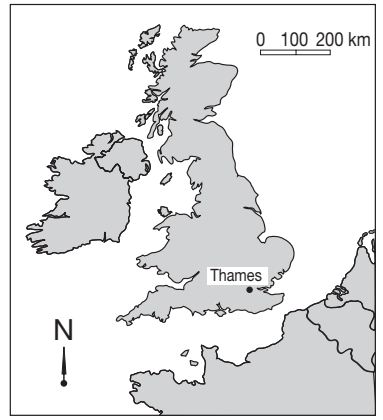

\begin{tabular}{|c|c|c|}
\hline \multicolumn{3}{|l|}{ KEY } \\
\hline Variable & \multicolumn{2}{|c|}{ Spatial Domain } \\
\hline $\begin{array}{l}\text { 1. MSLP } \\
\text { 2. MSLP } 1 \\
\text { 3. MSLP } \\
\text { AR2 }\end{array}$ & $\begin{array}{l}65-80^{\circ} \mathrm{N} \\
50-85^{\circ} \mathrm{N} \\
25-45^{\circ} \mathrm{N}\end{array}$ & $\begin{array}{l}45^{\circ} \mathrm{W}-110^{\circ} \mathrm{E} \\
115^{\circ} \mathrm{W}-100^{\circ} \mathrm{E} \\
25^{\circ} \mathrm{W}-35^{\circ} \mathrm{E}\end{array}$ \\
\hline $\begin{array}{l}\text { 4. }{\mathrm{Z} 500_{\mathrm{GR} 1}} \\
\text { 5. } \mathrm{Z} 500_{\mathrm{GR} 2} \\
\text { 6. }{\mathrm{Z} 500_{\mathrm{ATL}}}\end{array}$ & $\begin{array}{l}55-75^{\circ} \mathrm{N} \\
60-70^{\circ} \mathrm{N} \\
25-50^{\circ} \mathrm{N}\end{array}$ & $\begin{array}{l}80^{\circ} \mathrm{W}-0^{\circ} \mathrm{E} \\
40-50^{\circ} \mathrm{W} \\
70^{\circ} \mathrm{W}-40^{\circ} \mathrm{E}\end{array}$ \\
\hline $\begin{array}{l}\text { 7. } S_{\text {SIC }} \\
\text { 8. } S_{D S 1} C_{D S 2} \\
\text { 9. } S_{B A R}\end{array}$ & $\begin{array}{l}51-54^{\circ} \mathrm{N} \\
59-65^{\circ} \mathrm{N} \\
73-81^{\circ} \mathrm{N}\end{array}$ & $\begin{array}{l}49^{\circ}-52^{\circ} \mathrm{W} \\
61-60^{\circ} \mathrm{W} \\
25-57^{\circ} \mathrm{E}\end{array}$ \\
\hline
\end{tabular}

Fig. 1. (A) Spatial domains of the area averaged MSLP (mean sea level pressure; AR: Arctic, MED: Mediterranean), Z500 (North Atlantic geopotential height at $500 \mathrm{hPa}$; GR: Greenland, ATL: Atlantic) and SIC (sea-ice concentration; DS: Davis Straits, BAR: Barents Sea) attributes and the location of the gauging station for the River Thames at Teddington (B)

Global Sea-Ice Coverage (GICE) data set of the UKMO. Both sets of data were accessed via the British Atmospheric Data Centre (BADC). Monthly grids $\left(5^{\circ} \times 5^{\circ}\right)$ of Northern Hemisphere MSLP were obtained from the University Corporation for Atmospheric Research, USA. Domain averages of Z500 and MSLP were calculated for regions over Greenland and the Atlantic and Mediterranean, and March area averages of sea-ice were calculated for the Barents Sea and Davis Straits (see Fig. 1).
Monthly indices of POL are from the Climate Prediction Center, USA. POL was originally identified using rotated principal component analysis of $700 \mathrm{hPa}$ mean geopotential height anomalies in the Northern Hemisphere (Barnston \& Livezey 1987). The POL values are standardised amplitudes from a 3 mo period, centred on each calendar month (i.e. January POL is based on December to February $700 \mathrm{hPa}$ geopotential height anomaly fields). January values are, therefore, representative of the average winter POL amplitude. 
Monthly values of the Arctic Oscillation Index (AOI) are from the Department of Atmospheric Science, Colorado State University, USA (Thompson 2002). AOI is derived using principal component analysis of MSLP anomaly data (Trenberth \& Paolino 1980). During periods of high AOI, the westerly circulation is enhanced around the latitude of the British Isles (Delworth \& Dixon 2000, Wallace 2000).

Monthly values of central England temperatures (CET) were obtained from the Hadley Centre (UKMO) for Climate Prediction and Research, UK. T1 is the winter average (January-February) of the leading eigenvector of $5^{\circ} \times 5^{\circ}$ monthly mean sea surface temperature anomalies (SSTA) for the North Atlantic $\left(20\right.$ to $\left.80^{\circ} \mathrm{N}\right)$. This index was obtained from A. W. Colman \& M. Davey (pers. comm.) based on data from the UKMO Historical Sea Surface Temperature (MOHSST) data set. T1 accounts for $25 \%$ of the variability in North Atlantic SSTA. Positive winter values of T1 represent positive SSTA around Europe and the western Atlantic and are generally associated with above-average CET in the following summer (Colman 1997).

Finally, monthly mean naturalised river flows for the non-tidal Thames at Teddington were obtained from the UK Environment Agency (Davis 2000). Naturalised flows are adjusted to take into account water abstraction and artificial discharges, reducing human influences on the time series. The location of the gauging station is shown in Fig. 1.

\section{METHODOLOGY}

Four ES models were used to forecast mean flows in the River Thames for the mean of the summer months June to August $\left(Q_{\mathrm{JJA}}\right)$ and for August alone $\left(Q_{\mathrm{AUG}}\right)$ (Table 1). Model A employed 15 attributes listed in Table 1. Model B used all 6 Z500 and MSLP attributes, whereas Model C series employed only the Z500 variables. These combinations of attributes have been previously identified as the most promising seasonal predictors of low river flows in England and Wales (Wedgbrow 2003). Model D employed only $\mathrm{T} 1$ so that one set of forecasts could be directly compared with the previously modelled flows for the same river and period using JKR (Wilby et al. 2004). An inductive ES shell called See5 (RuleQuest Research) was employed rather than a rule-based

Table 1. Definition, spatial domain and source of attributes and the attributes available to each of the Expert System (ES) models A to D. Spatial domains of predictors 1 to 9 are plotted in Fig. 1

\begin{tabular}{|c|c|c|c|c|c|}
\hline Predictor & Domain & Source/URL & $\mathrm{A}$ & $\mathrm{B}$ & $\mathrm{C} \mathrm{D}$ \\
\hline $1 \mathrm{MSLP}_{\mathrm{MED}}$ & $\begin{array}{l}\text { Mean sea level pressure } \\
\text { (Mediterranean } 25-45^{\circ} \mathrm{N}, 25^{\circ} \mathrm{W}-35^{\circ} \mathrm{E} \text { ) }\end{array}$ & www.dss.ucar.edu/datasets & $\mathrm{x}$ & $\mathrm{x}$ & \\
\hline $2 \mathrm{MSLP}_{\mathrm{AR} 1}$ & $\begin{array}{l}\text { Mean sea level pressure } \\
\left(\text { Arctic } 65-80^{\circ} \mathrm{N}, 45^{\circ} \mathrm{W}-110^{\circ} \mathrm{E}\right)\end{array}$ & www.dss.ucar.edu/datasets & $\mathrm{x}$ & $\mathrm{x}$ & \\
\hline $3 \mathrm{MSLP}_{\mathrm{AR} 2}$ & $\begin{array}{l}\text { Mean sea level pressure } \\
\left(\text { Arctic } 50-85^{\circ} \mathrm{N}, 115^{\circ} \mathrm{W}-100^{\circ} \mathrm{E}\right)\end{array}$ & www.dss.ucar.edu/datasets & $\mathrm{x}$ & $\mathrm{x}$ & \\
\hline $4 \mathrm{Z}^{2} 00_{\mathrm{GR} 1}$ & $\begin{array}{l}\text { North Atlantic geopotential height } \\
\left.\text { (Greenland } 55-75^{\circ} \mathrm{N}, 80^{\circ} \mathrm{W}-0^{\circ} \mathrm{E}\right)\end{array}$ & www.badc.nerc.ac.uk/data & $\mathrm{x}$ & $\mathrm{x}$ & $\mathrm{x}$ \\
\hline $5 \mathrm{Z}^{2} 00_{\mathrm{GR} 2}$ & $\begin{array}{l}\text { North Atlantic geopotential height } \\
\left.\text { (Greenland } 60-70^{\circ} \mathrm{N}, 40-50^{\circ} \mathrm{W}\right)\end{array}$ & www.badc.nerc.ac.uk/data & $\mathrm{x}$ & $\mathrm{x}$ & $\mathrm{x}$ \\
\hline $6 \mathrm{Z} 500_{\mathrm{ATL}}$ & $\begin{array}{l}\text { North Atlantic geopotential height } \\
\text { (Atlantic/Mediterranean } 25-50^{\circ} \mathrm{N}, 70^{\circ} \mathrm{W}-40^{\circ} \mathrm{E} \text { ) }\end{array}$ & www.badc.nerc.ac.uk/data & $\mathrm{x}$ & $\mathrm{x}$ & $\mathrm{x}$ \\
\hline $7 \mathrm{SIC}_{\mathrm{DS} 1}$ & $\begin{array}{l}\text { Sea-ice concentration } \\
\left(\text { Davis Straits } 51-54^{\circ} \mathrm{N}, 49-52^{\circ} \mathrm{W}\right)\end{array}$ & www.dss.ucar.edu/datasets & $\mathrm{x}$ & & \\
\hline $8 \mathrm{SIC}_{\mathrm{DS} 2}$ & $\begin{array}{l}\text { Sea-ice concentration } \\
\text { (Davis Straits } 59-65^{\circ} \mathrm{N}, 61-60^{\circ} \mathrm{W} \text { ) }\end{array}$ & www.dss.ucar.edu/datasets & $\mathrm{x}$ & & \\
\hline $9 \mathrm{SIC}_{\mathrm{BAR}}$ & $\begin{array}{l}\text { Sea-ice concentration } \\
\left(\text { Barents Sea } 73-81^{\circ} \mathrm{N}, 25-57^{\circ} \mathrm{E}\right)\end{array}$ & www.dss.ucar.edu/datasets & $\mathrm{x}$ & & \\
\hline NAOI & North Atlantic Oscillation Index & www.cru.uea.ac.uk/cru/data & $\mathrm{x}$ & & \\
\hline AOI & Arctic Oscillation Index & www.atmos.colostate.edu/ao/Data & $\mathrm{x}$ & & \\
\hline SOI & Southern Oscillation Index & www.cru.uea.ac.uk/cru/data & $\mathrm{x}$ & & \\
\hline POL & Polar Eurasian pattern & www.cpc.ncep.noaa.gov/data & $\mathrm{x}$ & & \\
\hline CET & Central England temperature & $\begin{array}{l}\text { www.metoffice.com/research/ } \\
\text { hadleycentre/CR_data }\end{array}$ & $\mathrm{x}$ & & \\
\hline T1 & North Atlantic sea surface temperature & UK Meteorological Office & $\mathrm{x}$ & & $\mathrm{x}$ \\
\hline
\end{tabular}


ES, due to the lack of 'domain experts' from which forecasting rules could be obtained (Wedgbrow 2003).

Beginning with an initial training period of 1950 to 1970, each model was used to forecast river flow (cumecs) in the following summer from winter predictor variables (Table 1). Once an independent forecast had been produced, each model was retrained including the data for that target year. For example, independent forecasts for 1971 were derived from models trained on data for 1950 to 1970, and forecasts for 1972 were trained on 1950 to 1971, and so on until forecasts had been produced up to summer 2001.

\section{MODEL RESULTS}

Model skill was assessed using the standard error of the forecasts (SE), the percentage of explained variance $\left(R^{2}\right)$, the percentage of correct sign forecasts (CSF), the mean square skill score (MSSS) and root mean square skill score (RMSSS). MSSS and RMSSS are WMO preferred measures of long range forecasting skill and are defined in Eqs. (1) \& (2) (WMO 2002):

$$
\mathrm{MSSS}_{j}=1-\frac{\mathrm{MSE}_{j}}{\mathrm{MSE}_{c j}}
$$

for a forecast $j$ and forecast of climatology $c j$ where MSE is Mean Squared Error, and

$$
\operatorname{RMSSS}=1-(1-\mathrm{MSSS})^{1 / 2}
$$

Positive MSSS and RMSSS scores indicate improvements upon a forecast based on climatology. Model skill was also compared with that obtained from a naïve autocorrelation ES model using winter values (January-February) of the target variable $\left(Q_{\mathrm{JF}}\right)$ as the predictor of summer flows. Climatology was calculated as the long-term average (LTA) prior to each forecast year.

Tables 2 \& 3 show that the ES models were substantially more skilful than the naïve model for all diagnostics for both $Q_{\mathrm{JJA}}$ and $Q_{\mathrm{AUG}}$ except for $\mathrm{R}^{2}$. Values of $\mathrm{R}^{2}$ were only statistically significant for Models B $(27 \%)$ and C (20\%) for $Q_{\mathrm{JJA}}$. The ES models correctly forecast the sign of the flow anomaly (with respect to climatology) for up to 77 and $71 \%$ of $Q_{\mathrm{AUG}}$ and $Q_{\mathrm{JJA}}$ respectively. Using a bootstrapping procedure to randomly sample (with replacement) the flow anomaly data, the critical value for CSF was found to be $65 \%$ for $\mathrm{p}=0.95$ (both $Q_{\mathrm{AUG}}$ and $Q_{\mathrm{JJA}}$ flows). Therefore, these results are statistically significant at the 0.05 level.

MSSS and RMSSS reveal no gain in skill over climatology using the large-scale winter attributes in an ES to forecast absolute flows, and only marginal gains in skill using JKR (MSSS < 0.2, RMSS =0.1). Tables $2 \& 3$
Table 2. Model skill for forecasts of August flow (cumecs) $\left(Q_{\mathrm{AUG}}\right)$ in the River Thames for the verification period 1971 to 2001. "Diagnostics were statistically significant at the 0.05 level. CSF: correct sign forecast; MSSS: mean square skill score; RMSSS: root mean square skill score; JKR: Jack Knife Regression

\begin{tabular}{|lccccc|}
\hline Model & $\begin{array}{c}\mathrm{SE} \\
\text { (cumecs) }\end{array}$ & $\begin{array}{c}\mathrm{R}^{2} \\
(\%)\end{array}$ & $\begin{array}{c}\text { CSF } \\
(\%)\end{array}$ & $\begin{array}{c}\text { MSSS } \\
\text { (units) }\end{array}$ & $\begin{array}{c}\text { RMSSS } \\
\text { (units) }\end{array}$ \\
\hline$Q_{\mathrm{JF}}$ & 56 & 5 & 0 & -96.2 & -8.9 \\
$\mathrm{~A}$ & 11 & 1 & 58 & -0.7 & -0.3 \\
$\mathrm{~B}$ & 9 & 3 & $77^{*}$ & -0.3 & -0.1 \\
$\mathrm{C}$ & 9 & 8 & 65 & -0.3 & -0.1 \\
$\mathrm{D}$ & 9 & 2 & $68^{*}$ & -0.1 & -0.1 \\
$\mathrm{JKR}$ & 7 & $17^{*}$ & $68^{*}$ & 0.2 & 0.1 \\
\hline
\end{tabular}

Table 3. As for Table 2, but for mean June to August flow (cumecs) $\left(Q_{\mathrm{JJA}}\right)$

\begin{tabular}{|lcrrrr|}
\hline Model & $\begin{array}{c}\mathrm{SE} \\
\text { (cumecs) }\end{array}$ & $\begin{array}{c}\mathrm{R}^{2} \\
(\%)\end{array}$ & $\begin{array}{c}\text { CSF } \\
(\%)\end{array}$ & $\begin{array}{c}\text { MSSS } \\
\text { (units) }\end{array}$ & $\begin{array}{c}\text { RMSSS } \\
\text { (units) }\end{array}$ \\
\hline $\mathrm{Q}_{\mathrm{JF}}$ & 57 & 5 & 0 & -58.8 & -6.7 \\
$\mathrm{~A}$ & 10 & 11 & 55 & -0.2 & -0.1 \\
$\mathrm{~B}$ & 10 & $27^{*}$ & 65 & -0.3 & -0.1 \\
$\mathrm{C}$ & 11 & $20^{*}$ & $71^{*}$ & -0.4 & -0.1 \\
$\mathrm{D}$ & 9 & 1 & 65 & -0.3 & -0.1 \\
$\mathrm{JKR}$ & 10 & 13 & 65 & 0.1 & 0.1 \\
\hline
\end{tabular}

show that for forecasts of the whole range of flows Model D produced either less skilful or equivalent forecasts to the JKR method. The percentages of correct sign forecasts were identical for the ES and the JKR for both forecast periods.

Figs. 2 \& 3 show that all ES models correctly forecast below-average flows for the dry summers of 1976 , 1984, 1989 to 1992, 1995 and 1997 except for Model D for August 1976 and Model A for August 1997. The JKR model, however, failed to predict below-average flows in both August 1997 and the summer of 1997. Forecasts of significantly below- (or above-) average flows are clearly possible using the climatological mean, while forecasts based on the naïve model suggested much higher flows than were actually observed (e.g. + 223 cumecs for August 1995)

To further assess forecast skill for low flow, 2 contingency tables were produced for each model: the first for forecasts that flow in the River Thames will be in the lowest decile ( 0 to 10 th percentile) of the LTA flow, and the second for forecasts that flow will be in the lowest quartile (0 to 25th percentile) of LTA flow. All percentiles were derived from the LTA prior to each forecast year. The category forecasts were verified using the percent correct (PC) and residual sum of squares (RSS) diagnostics. Note that sample sizes for 


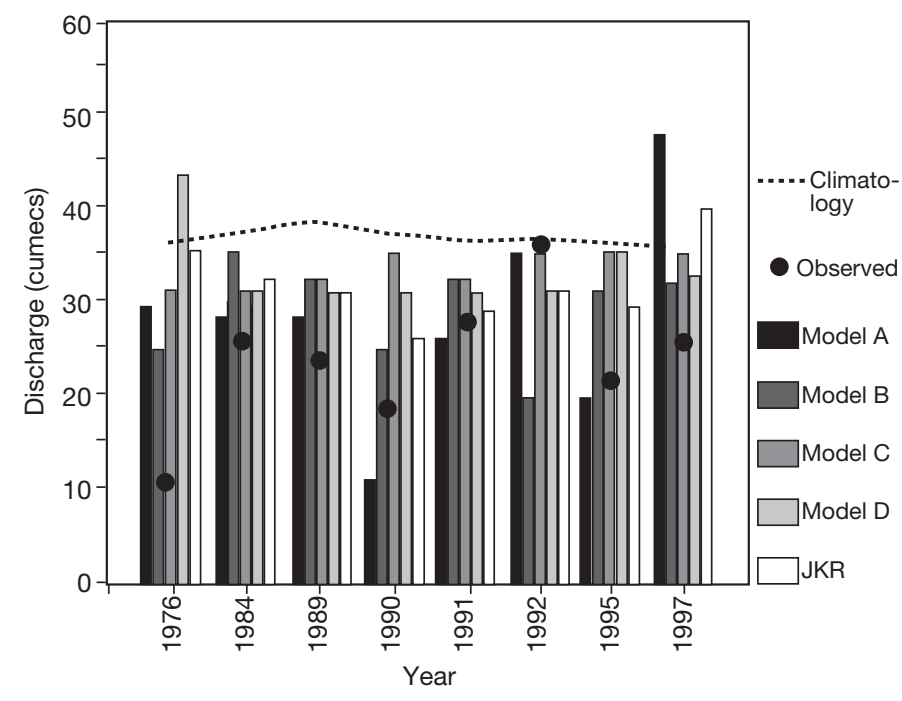

Fig. 2. Observed and forecast mean August flow in the River Thames for selected low-flow years. JKR: Jack Knife Regression

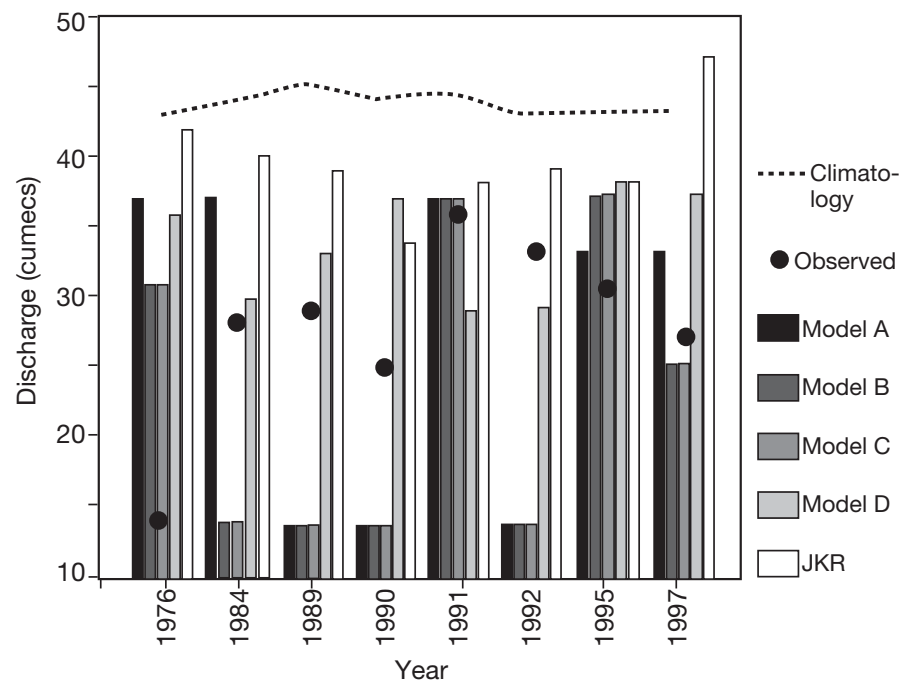

Fig. 3. Observed and forecast mean June to August flow in the River Thames for selected low-flow years

years with low-flow events are small (August 0 to 10th percentile $n=7$, JJA $n=5$; August 0 to 25th percentile $\mathrm{n}=14$, JJA $\mathrm{n}=9$ ). Consequently, there is insufficient information in the time series to generate forecasting rules that are robust to the full range of inter-annual variability. However, the ES could be re-trained as additional data become available.

Tables 4 \& 5 show the results for forecasting low flows. The greatest improvements upon the naïve model for forecasts of low $Q_{\mathrm{AUG}}$ were for Model A, which correctly forecast $79 \%$ of the lowest 25 th percentile flows compared to $36 \%$ using the naïve model. This value is statistically significant at the 0.05 level as
Table 4. Summary of verification measures for forecasts that $Q_{\mathrm{AUG}}$ and $Q_{\mathrm{JJA}}$ would be in the 0 to 10 th percentile of the long-term average. Number of extreme low-flow events: $\mathrm{n}=7$ (August), $\mathrm{n}=5$ (mean JJA). ${ }^{*}$ Percent Correct (PC) is statistically significant at the 0.05 level. RSS: Residual Sum of Squares

\begin{tabular}{|lcccc|}
\hline \multirow{2}{*}{ Model } & \multicolumn{2}{c}{$Q_{\mathrm{AUG}}$} & \multicolumn{2}{c|}{$Q_{\mathrm{JJA}}$} \\
& PC (\%) & RSS (units) & PC (\%) & RSS (units) \\
\hline$Q_{\mathrm{JF}}$ & $29^{*}$ & 20 & 0 & 20 \\
$\mathrm{~A}$ & $43^{*}$ & 7 & $60^{*}$ & 5 \\
$\mathrm{~B}$ & $29^{*}$ & 17 & $80^{*}$ & 1 \\
$\mathrm{C}$ & 0 & 28 & $60^{*}$ & 5 \\
$\mathrm{D}$ & 0 & 25 & 0 & 17 \\
$\mathrm{JKR}$ & 14 & 15 & 0 & 17 \\
\hline
\end{tabular}

Table 5. As for Table 4, but for the 0 to 25 th percentile of the long-term average. Number of extreme low-flow events: $\mathrm{n}=$ 14 (August), $\mathrm{n}=9$ (JJA)

\begin{tabular}{|lcccc|}
\hline \multirow{2}{*}{ Model } & \multicolumn{2}{c}{$Q_{\text {AUG }}$} & \multicolumn{2}{c|}{$Q_{\text {JJA }}$} \\
& PC (\%) & RSS (units) & PC (\%) & RSS (units) \\
\hline$Q_{\mathrm{JF}}$ & $36^{*}$ & 12 & 0 & 9 \\
$\mathrm{~A}$ & $79^{*}$ & 11 & $67^{*}$ & 11 \\
$\mathrm{~B}$ & $50^{*}$ & 15 & $89^{*}$ & 9 \\
$\mathrm{C}$ & 7 & 19 & $7^{*}$ & 12 \\
$\mathrm{D}$ & $29^{*}$ & 15 & $33^{*}$ & 19 \\
$\mathrm{JKR}$ & $50^{*}$ & 8 & 11 & 11 \\
& & & & \\
\hline
\end{tabular}

bootstrapping suggests a critical value of $16 \%$ for PC for August ( $p=0.95$ ).

The greatest gains for forecasts of low $Q_{\mathrm{JJA}}$ were for Model B, which correctly forecast $80 \%$ of summers with flow the 10 th percentile, and $89 \%$ of summers with flow the 25 th percentile. These values are statistically significant (the bootstrap estimate for the critical value for PC of $Q_{\mathrm{JJA}}$ was $32 \%$ ). The forecasting skill of the JKR model for low flows was generally superior to Model D, which used the same large-scale attribute except for forecasts of mean June to August flows $\leq$ the 25 th percentile (PC was $33 \%$ for Model D, compared with $11 \%$ for the JKR model). However, Model A consistently outperformed JKR for forecasts of low $Q_{\text {AUG }}$ flow, whereas Models A, B and C were superior for $Q_{\mathrm{JJA}}$ (Table 5).

\section{DISCUSSION}

The best seasonal forecasting model varied with the period of flow forecast, the measure of skill used and the river flow percentile category. For example, in terms of percentage of variance explained Model B was best for $Q_{\mathrm{JJA}}\left(\mathrm{R}^{2}=27\right)$. In terms of percentage of correct sign forecasts, the best scores were for Model B 
for $Q_{\mathrm{AUG}}(77 \% \mathrm{CSF})$ and Model C for $Q_{\mathrm{JJA}}(71 \% \mathrm{CSF})$. The highest percentage of correct forecasts was obtained using Model B for forecasts that $Q_{\mathrm{JJA}}$ would be $\leq$ the 25 th percentile ( $89 \%$ PC). Model B emerges as the best model overall, implying some seasonal forecast value in the circulation indices MSLP and Z500.

For forecasts across the whole range of flow values, there was no gain in skill over using climatology. The physical properties of the River Thames basin may contribute to the relatively low levels of skill, as the River Thames catchment has modest levels of influence from groundwater (Base Flow Index 0.64). For example, January-February mean flows in the River Thames are significantly correlated with river flow in March through to May $(r=0.45,0.27,0.35$ respectively), but this should have been more advantageous to the naïve model. Previous research suggests catchments with medium levels of groundwater (e.g. the River Medway in the south of England) may be more predictable (Wilby 2001, Wedgbrow 2003). However, a gain in skill over a climatological reference forecast is a minimum requirement for a useful hydrological or hydroclimatological model (Legates \& McCabe 1999). In support of this, when model skill is placed into context for forecasting low flows only, the ES models correctly forecast up to $79 \%$ of August months and up to $89 \%$ of summers with flows in the lowest quartile.

The amount of variance in river flows explained by the ES was low $(<27 \%)$, but forecasts of the sign of the expected flow anomaly were correct 55 to $77 \%$ of the time. Although the ES did not always anticipate the magnitude of the anomalies, there is still a distinct advantage over the climatological forecasts which theoretically could signal below average flows on $50 \%$ of years. Therefore, forecasts based on ES may be of value to water resource managers. Long lead forecasts of summer river flows could help focus monitoring efforts and provide early warning of relatively low flows, which may lead to possible water supply and/or water quality problems (N. Kennedy pers. comm., H. Smithers pers. comm.). However, forecast certainty must be further investigated to identify the conditions conducive to model success by examining the robustness of the rules under different precursor situations.

In general, the most useful attributes were area averages of winter Z500 and MSLP over parts of the North Atlantic, Mediterranean and the Arctic. Area averaged geopotential heights over the Arctic/North Atlantic were also identified as useful predictors for river flows in the Thames using JKR models (Wilby et al. 2004). Less useful were the winter indices of large-scale circulation patterns (such as the NAOI, AOI, POL and SOI) and North Atlantic SST (T1). However, it is likely that different combinations of attributes may prove useful for seasonal forecasts of low flows in other months/seasons or locations. For example, LloydHughes \& Saunders (2002) have highlighted the skill of ENSO for forecasting spring-time rainfall anomalies across NW Europe.

\section{CONCLUSIONS}

Using an Expert System (ES), summer flows for the River Thames (1971 to 2001) were forecast with up to 6 mo lead-time from readily available climate data for the preceding winter months. ES models achieved modest gains in skill over a naïve autocorrelation model for low flows, but no gain over climatology for forecasts of the whole range of flow. This outcome reflects the high level of monthly autocorrelation and low variability of flows in the River Thames, low information content in the training data, or low predictability from the chosen attributes. However, the ES models did successfully forecast the correct sign of August flow anomalies up to $77 \%$ of the time and for June to August $71 \%$ of the time. These results are statistically significant (0.05 level) and are an improvement upon climatology. The ES models correctly forecast low flows in August and summer 79 and $89 \%$ of the time, respectively. These results were also statistically significant. Finally, the models correctly predicted belowaverage flows for the UK droughts in 1976, 1984, 1989 to 1992, 1995 and 1997. Clearly, these extreme events would not have been captured by the climatological mean.

Even the best ES model of the whole range of flows provided no gain in skill over the JKR model. However, for forecasts of only the lowest quartile and decile flows 3 out of $4 \mathrm{ES}$ models were superior to the JKR model. This may reflect advantages of the non-linear transfer functions of the ES.

The ES methodology was probably confounded by insufficient information in the time series to generate robust forecasting rules. Unfortunately, in common with other statistical models, many ES algorithms are affected by noisy data, resulting in model instability and/or overfitting (Domingos 1996, Geurts et al. 2001). However, this drawback was partly due to the limited explanatory power of the predictors and the complexity of the hydrometeorological relationships. This underlines the fact that ESs are subject to the same limitations imposed by data quality and quantity as other empirical methods.

Regardless of technique, all empirical methods are restricted by the natural limits of predictability of the atmosphere and by the uncertainty surrounding the future climate (Anderson 2000). Rather than employing expensive dynamical models or statistics bound by unrealistic data constraints, methods such as ES could 
be a useful technique for capturing non-linear climate relationships, enabling long-range predictions until the dynamics are better understood.

The rules created by the ES employed in this study are tailored specifically for the River Thames, reflecting the complex relationships between large-scale atmospheric circulation and the physical properties of the River Thames basin and resultant river flows. It could be argued that creating tailored rules maximises the forecasting potential for an individual river. However, it also means that the ES rules were derived from a relatively small sample of data and may not be robust. Future models could be built from a much greater number of rivers, for example using the Flow Regimes from International Experiment and Network Data (FRIEND) data set which contains over 1100 gauging stations across the UK (Gustard \& Cole 2002).

Other future research priorities include investigating different forecast periods and/or new attributes. For example, the averaging period of target flows may be tailored to an individual catchment depending on the rainfall-runoff response time (Sefton \& Howarth 1998), whilst future models could include variables such as soil moisture, SSTs other than from the North Atlantic and spring predictors (although this would decrease the forecast lead time). However, extra variables may not necessarily lead to substantial increases in model accuracy, especially if they are partially correlated with existing variables. Whether or not the predictors are available in real-time is also a consideration.

Acknowledgements. Geopotential heights were supplied by the British Atmospheric Data Centre (BADC). Mean sea level pressure fields were provided by the Scientific Computing Division of the National Center for Atmospheric Research (NCAR).

\section{LITERATURE CITED}

Anderson D (2000) Forecasting for all seasons. The challenges of long-range weather prediction. Phys World 13:43-48

Barnston AG, Livezey RE (1987) Classification, seasonality and persistence of low-frequency atmospheric circulation patterns. Mon Weather Rev 115:1083-1126. Also available at: http://www.cpc.ncep.noaa.gov/teledoc/telepatcalc.html

Barry RG, Carleton AM (2001) Synoptic and dynamic climatology. Routledge, London

Colman AW (1997) Prediction of summer central England temperature from preceding North Atlantic winter sea surface temperature. Int J Climatol 17:1285-1300

Conway BJ (1989) Expert Systems and weather forecasting. Meteorol Mag 118:23-30

Davis RJ (2000) An investigation into hydrological variability and change in the Thames Region. Hydrology and Hydrometry Report 00/02, Water resources. Environment Agency, Reading

Delworth TL, Dixon KW (2000) Implications of the recent trend in the Arctic/North Atlantic oscillation for the
North Atlantic thermohaline circulation. J Clim 13(21): $3721-3727$

Domingos P (1996) Unifying instance-based and rule-based induction. Mach Learn 24:141-168

Forsyth R, Naylor C (1985) The hitch-hikers guide to artificial intelligence. Chapman \& Hall, London

Geurts P, Olaru C, Wehenkel L (2001) Improving the bias/ variance tradeoff of decision trees: towards soft induction. Eng Intelligent Syst 4:195-204

Goddard L, Mason SJ, Zebiak SE, Ropelewski CF, Basher R, Cane MA (2001) Current approaches to seasonal-tointerannual climate predictions. Int $\mathrm{J}$ Climatol 21: $1111-1152$

Gustard A, Cole GA (2002) FRIEND - a global perspective 1998-2002. Centre for Ecology and Hydrology (CEH), Wallingford. Also available at http://www.nerc-wallingford. ac.uk/ih/friend

Honghua D, Qisong Z, Zhaoxin Z (1987) An Expert System for predicting the regional heavy rain. Adv Atmos Sci 4(4): 496-505

Jackson P (1999) Introduction to Expert Systems, 3rd edn. Addison-Wesley, Harlow

Kilsby CG, Cowpertwait PSP, O'Connell PE, Jones PD (1998) Predicting rainfall statistics in England and Wales using atmospheric circulation variables. Int $\mathrm{J}$ Climatol 18: 523-539

Kumar VR, Chung CYC, Lindley CA (1994) Toward building an expert system for weather forecasting operations. Expert Syst Appl 7(2):73-381

Kumar KK, Soman MK, Kumar KR (1995) Seasonal forecasting of Indian summer monsoon rainfall: a review. Weather 50(12): 449-467

Landman WA, Mason SJ (1999) Change in the association between Indian Ocean sea surface temperatures and summer rainfall over South Africa and Namibia. Int J Climatol 19:1477-1492

Legates DR, McCabe GJ (1999) Evaluating the use of 'goodness-of-fit' measures in hydrologic and hydroclimatic model validation. Water Resour Res 35(1):233-241

Lloyd-Hughes B, Saunders MA (2002) Seasonal prediction of European spring precipitation from ENSO and local sea surface temperatures. Int J Climatol 22:1-14

Quinlan JR (1993) C4.5 programs for machine learning. Morgan Kauffman, San Mateo

Reason CJC, Mulenga H (1999) Relationships between South African rainfall and SST anomolies in the southwest Indian Ocean. Int J Climatol 19:1651-1673

Rodda JC, Rodda HJE (1999) Hydrological forecasting. Dealing with natural disasters: achievements and new challenges in science, technology and engineering. The Royal Society, London, p 75-79

Rodionov SN, Assel R (1999) Laurentian Great Lakes ice cover and atmospheric teleconnection patterns: a decision tree analysis. Proc 8th Conf Climate Variations, American Meteorological Society, Denver, CO

Rodionov SN, Martin JH (1996) A knowledge-based system for the diagnosis and prediction of short-term climatic changes in the North Atlantic. J Clim 9(8): 1816-1823

Rodionov SM, Martin JH (1999) An expert system-based approach to prediction of year-to-year climatic variation in the North Atlantic region. Int J Climatol 19:951-974

Sefton CEM, Howarth SM (1998) Relationships between dynamic response characteristics and physical descriptors in catchments in England and Wales. J Hydrol 211:1-6

Solman SA, Nunez MN (1999) Local estimates of global climate change: a statistical downscaling approach. Int J Climatol 19:835-861 
Thompson DWJ (2002) Annular modes in the extratropical circulation. Part 1: Month to month variability. J Clim 13: 1000-1016

Trenberth KE, Paolino DA (1980) The northern hemisphere sea-level pressure data set: trends, errors and discontinuities. Mon Weather Rev 108:855-872

Wallace JM (2000) North Atlantic oscillation/annular mode: two paradigms - one phenomenon. Q J R Meteorol Soc 126:791-805

Wedgbrow CS (2003) Seasonal forecasting of low river flow in England and Wales using an Expert System. PhD thesis, University of Derby

Wilby RL (1998) Statistical downscaling of daily precipitation using daily airflow and seasonal teleconnection indices. Clim Res 10:163-178

Wilby RL (2001) Seasonal forecasting of river flows in the

Editorial responsibility: Allen H. Perry,

Swansea, UK
British Isles using North Atlantic pressure patterns. J Chart Inst Water Environ Manag 15:56-63

Wilby RL, Wigley TML (2000) Precipitation predictors for downscaling: observed and general circulation model relationships. Int J Climatol 20:641-661

Wilby RL, Wedgbrow CS, Fox HR (2004) Seasonal predictability of the summer hydrometeorology of the River Thames, UK. J Hydrol 295:1-16

WMO (World Meteorological Organization) (2002) Standardized verification systems (SVS) for long range forecasts (LRF). New attachment II-9 to the manual on the GDPS (WMO No.485), Vol 1. WMO, Geneva

WMO (World Meteorological Organization) (2003) Commission for basic systems. Proc Workshop Global Producers of seasonal to interannual forecasts, 10-13 Feruary 2003. WMO, Geneva

Submitted: November 11, 2004; Accepted: February 15, 2005 Proofs received from author(s): March 7, 2005 